\title{
The effect of continuous positive airway pressures on lung volumes in tetraplegic patients
}

\author{
LA Harvey ${ }^{1}$ and ER Ellis ${ }^{2}$ \\ ${ }^{I}$ Physiotherapy Department, The Prince Henry Hospital, Sydney; ${ }^{2}$ School of Physiotherapy, Faculty of Health \\ Sciences, The University of Sydney, Sydney, Australia
}

\begin{abstract}
Continuous positive airway pressure (CPAP) is widely advocated for the treatment of respiratory complications. However the effects of CPAP on the respiratory function of tetraplegic patients have not yet been investigated. The purpose of this study was to examine the effects of breathing with different levels of CPAP on the relationship between closing volume $(\mathrm{CV})$ and functional residual capacity (FRC) in ten recently injured, but otherwise healthy tetraplegic patients with lesions between the fourth and eighth cervical segments. Lung volumes were measured before, during and after $32 \mathrm{~min}$ of zero end-expiratory pressure and 5 and $10 \mathrm{~cm} \mathrm{H}_{2} \mathrm{O}$ of CPAP. FRC was measured by the open-circuit nitrogen washout method and $\mathrm{CV}$ was measured by the single breath nitrogen washout method. FRC was unaffected by zero end-expiratory pressure, but both $5 \mathrm{~cm} \mathrm{H}_{2} \mathrm{O}$ and $10 \mathrm{~cm} \mathrm{H}_{2} \mathrm{O}$ of CPAP caused significant increases in FRC. FRC returned to pre-CPAP values by the first minute after removal of 5 and $10 \mathrm{~cm} \mathrm{H}_{2} \mathrm{O}$ of CPAP. We were unable to measure CVs in any subjects. It was concluded that 5 and $10 \mathrm{~cm} \mathrm{H}_{2} \mathrm{O}$ of CPAP increase FRC in healthy tetraplegic individuals, but that these increases are rapidly lost with the subsequent removal of CPAP. These results suggest that CPAP may have a role in the treatment and prevention of respiratory complications in tetraplegics.
\end{abstract}

Keywords: tetraplegia; continuous positive airway pressure; atelectasis

\section{Introduction}

Continuous positive airways pressure (CPAP) therapy is widely used to prevent and treat atelectasis. ${ }^{1,2,3,4}$ It is believed to increase functional residual capacity (FRC) and widen the gap between FRC and closing volume $(\mathrm{CV})$, reducing the likelihood of airway closure during tidal breathing. ${ }^{4,5}$ It has been hypothesised that, by preventing airway closure within tidal breathing, atelectasis can be treated and prevented with CPAP. ${ }^{4}$

There are a number of studies that have examined the effect of CPAP on FRC in both healthy subjects $^{7,8,9,10}$ and in various patient populations. ${ }^{10,11}$ These studies have reported significant increases in FRC with the application of CPAP. In addition, a number of more clinically orientated studies have examined the effectiveness of CPAP for the treatment and prevention of various respiratory conditions, including atelectasis. ${ }^{1,2,4,12}$ These studies have reported positive effects from the periodic application of CPAP.

Tetraplegics are at particular risk of atelecta$\operatorname{sis}^{13,14,15,16}$ both because of the inactivity they

Correspondence: L Harvey, Physiotherapy Department, The Prince Henry Hospital, Anzac Parade, Little Bay, NSW, Australia 2036 experience and because of respiratory muscle denervation. ${ }^{15,17,18,19}$ To date no studies have looked at the possible uses of CPAP for the treatment and prevention of respiratory complications (other than sleep apnea) in such people, or for that matter, in subjects with similar patterns of respiratory neuromuscular weakness. This study, therefore, was designed to determine the effect of CPAP on the respiratory function of healthy people with tetraplegia. Specifically, the aim was to examine the effects of 5 and $10 \mathrm{~cm} \mathrm{H}_{2} \mathrm{O}$ of CPAP on the relationship between $\mathrm{CV}$ and FRC.

\section{Methods}

Subjects

Ten male subjects participated in the study. All subjects were either inpatients or had recently been discharged from a specialist spinal injuries unit. All had sustained a clinically complete (motor only) cervical spinal cord injury with lesions between the fourth and eighth cervical segments, as determined by a standard clinical neurological examination. Subjects were healthy, with no history of respiratory disease. 
Approval for all procedures was given by the institution's Human Ethics Committee and all subjects gave their informed written consent to participate in the study.

\section{Testing protocol}

Subjects were required to attend the respiratory laboratory on three separate occasions. With two exceptions, each visit was separated by at least $24 \mathrm{~h}$ and by no more than 1 week. In one subject the interval between two tests was 25 days, and in another 33 days. Subjects were asked to refrain from smoking or eating large meals for a $3 \mathrm{~h}$ period prior to each test. All testing was done with the subject sitting in his own wheelchair. Restraining straps were removed, and any restrictive garments were loosened.

On the first visit subjects were familiarised with all lung function testing procedures. On this and each subsequent visit the same format was followed. Initially vital capacity (VC), CV and FRC were measured, in that order. Two consecutive measurements were taken of each lung volume and averaged. At least $2 \mathrm{~min}$ were allowed between measuring $\mathrm{CV}$ and FRC, and 5 min were allowed between subsequent measurements of FRC.

On each visit, measurements of lung volumes were made, and then the subjects were required to breathe for $32 \mathrm{~min}$ whilst one of three airway pressures was maintained. The order of pressure application over the three visits was randomised. In this way subjects could act as their own controls. The three pressures were zero end-expiratory pressure, $5 \mathrm{~cm} \mathrm{H}_{2} \mathrm{O}$ of CPAP and $10 \mathrm{~cm} \mathrm{H}_{2} \mathrm{O}$ of CPAP. The zero end-expiratory pressure was used to control for the effects of the testing system and testing protocol on respiratory function. CPAPs of 5 and $10 \mathrm{~cm} \mathrm{H}_{2} \mathrm{O}$ were chosen to represent the range of pressures most commonly used in clinical settings.

Closing volume and FRC were measured 8 and $12 \mathrm{~min}$ after the application of CPAP, respectively. Closing volume was measured again at $20 \mathrm{~min}$ and FRC was measured again at $22 \mathrm{~min}$. Functional residual capacity was then measured at 1 and $21 \mathrm{~min}$ following the removal of CPAP and $\mathrm{CV}$ was measured at 11 and 31 min following the removal of CPAP.

\section{Instrumentation}

Functional residual capacity was measured by the open-circuit nitrogen washout method. Closing volume was measured using the single breath nitrogen $\left(\mathrm{SBN}_{2}\right)$ washout method. ${ }^{20}$ Measurement of FRC, CV and VC were made with a computerised pulmonary function testing system (SensorMedics 2200) which incorporated pneumatically controlled valves for switching between $\mathrm{O}_{2}$ and room air (see Figure 1). Precise measurement of $\mathrm{CV}$ is dependent on subjects maintaining an expiratory flow rate of between 0.3 and $0.61 . \mathrm{min}^{-1}$. Subjects were instructed to maintain, as far as possible, the required

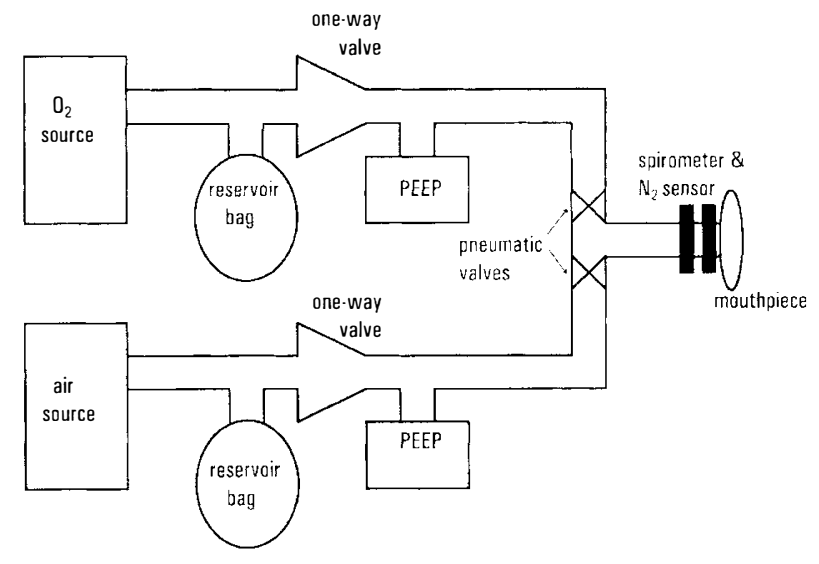

Figure 1 The Sensor Medics Circuitry incorporating the two CPAP circuits

flow rates. They were given feedback about their expiratory flow rates from a computer monitor which indicated when the target flow rates had been obtained.

A system was designed to enable CPAP to be administered via the mouthpiece and associated circuitry of the testing system (see Figure 1). Two identical CPAP systems were set up to maintain the CPAP both when the subjects were breathing $100 \% \mathrm{O}_{2}$ for the measurement of FRC and $\mathrm{CV}$, and when the subjects were breathing room air between these tests. The pneumatic valves incorporated within the testing system were used to switch between the two CPAP circuits. Subjects wore a nose-clip throughout the testing sessions. In this way both CV and FRC could be measured whilst maintaining CPAP. The CPAP was maintained using a continuous flow system (60 $1 . \mathrm{min}^{-1}$ ) that incorporated a 5 litre anaesthetic bag on the inspiratory limb and a threshold resistor valve (Vital Signs PEEP valve) on the expiratory limb of each of the two circuits. One-way valves were used to prevent rebreathing.

The mass flow sensor was calibrated at the beginning of each testing session and the $\mathrm{N}_{2}$ analyser was calibrated prior to each $\mathrm{CV}$ and FRC measurement. All PEEP valves were initially tested to ensure they were maintaining the desired pressures. In addition, airway pressure was monitored throughout testing by a piezoelectric pressure transducer, placed just distal to the mouthpiece.

\section{Analysis}

From the measurement of $\mathrm{VC}, \mathrm{CV}$ and FRC, values were derived for residual volume (RV) and total lung capacity (TLC). A mean for each of these lung volumes was calculated from all pre-CPAP lung volume measurements. All data was expressed as a percentage of predicted values for able-bodied subjects, as established by the European Community for Coal and Steel. $^{21}$ Intra-class correlation coefficients (type $2,1^{22}$ ) were generated to test the within-testing-session 
and between-testing-session reliability of pre-CPAP FRC data.

All inferential analyses of the effect of CPAP on FRC were performed on the FRC data expressed as a percentage of predicted FRC values. Pressure and time were crossed factorially in a $3 \times 5$ repeated measures ANOVA to test for the effect of pressure, time and the interaction of pressure and time. To determine the effect of each level of CPAP on FRC, three separate one-way repeated measures ANOVAs were used. A Dunnett's post hoc test was then performed to determine if any significant differences existed between pre-CPAP FRC values and the subsequent FRC values. ${ }^{23}$

\section{Results}

Ten subjects completed all testing sessions (mean age 32.9 years with SD of 10.4; height $180.5 \mathrm{~cm}( \pm 7.7)$; weight $76.4 \mathrm{~kg}( \pm 15)$. Two subjects had a $\mathrm{C} 4$ lesion, five subjects had a C5 lesion, one subject had a C7 lesion and two subjects had a $\mathrm{C} 8$ lesion. Two subjects had some intact sensation below the level of the lesion (ie, sensory incomplete injuries). All subjects had sustained their injury no more than 5 years prior to testing (median time since injury 12.5 months with an interquartile range of $10.3-18.5$ months).

Three of the ten subjects were smokers at the time of testing. The number of cigarettes smoked varied from 12 to 50 cigarettes per day. In addition, five subjects had previously been smokers, with two of these subjects ceasing smoking at the time of their accident and the remaining three subjects ceasing smoking up to 25 years prior to testing. Two subjects had never smoked.

The mean $( \pm \mathrm{SD}) \mathrm{VC}, \mathrm{TLC}, \mathrm{RV}$ and FRC were $2.73( \pm 1.03), 5.94( \pm 1.26), 3.21( \pm 1.22)$ and 3.83 $( \pm 1.22)$, respectively, corresponding to $50.4( \pm 19.4)$, $80.3( \pm 12.5), 171.1( \pm 56.3)$ and $110.3( \pm 30.5)$ per cent of predicted values. It was not possible to detect a $\mathrm{CV}$ in any of the subjects, with or without the application of CPAP. That is, there was no distinct onset of phase 4 with which to identify a CV. This was despite the fact that all subjects could maintain satisfactory expiratory flow rates.

The procedure used for measuring FRC in this study was highly reliable. The intra-class correlation coefficient describing the agreement between repeat measurements made prior to the application of CPAP was 0.98 . The intra-class correlation coefficients describing agreement between testing sessions were 0.88 for the first measurement made in each session, and 0.92 for the second measurement made in each session. This means that more than $88 \%$ of the observed between-subject variability was attributable to real differences between subjects, rather than to measurement error.

The FRC data is presented in Figure 2. Functional residual capacity increased with the application of zero end-expiratory pressure and with 5 and $10 \mathrm{~cm} \mathrm{H}_{2} \mathrm{O}$ of

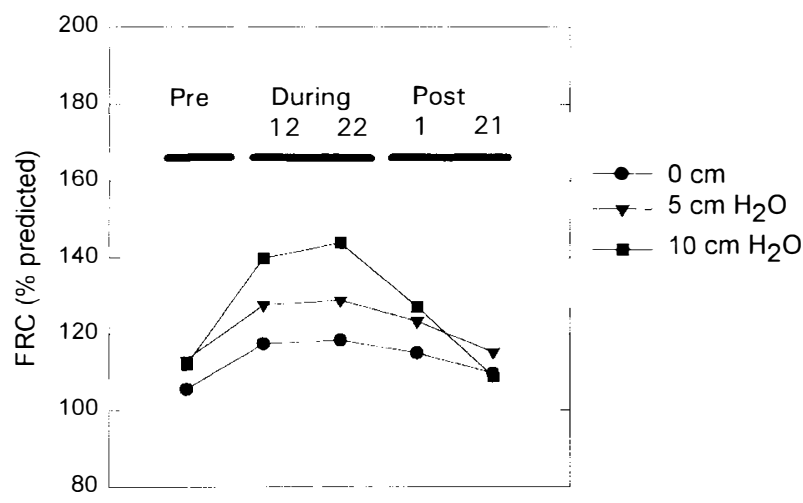

Figure 2 FRC ( $\%$ predicted $)$ pre, during and post application of zero end-expiratory pressure and 5 and $10 \mathrm{~cm}$ $\mathrm{H}_{2} \mathrm{O}$ CPAP. The squares represent $10 \mathrm{~cm} \mathrm{H}_{2} \mathrm{O}$ of CPAP, the triangles $5 \mathrm{~cm} \mathrm{H}_{2} \mathrm{O}$ of $\mathrm{CPAP}$ and the circles zero endexpiratory pressure

CPAP and then decreased to near pre-CPAP values with its subsequent removal. The effects of pressure $(P=0.042)$, time $(P<0.001)$ and the interaction of pressure and time $(P<0.001)$ were significant. The shape of the FRC-time relationship for the three conditions and the finding of an interactive effect of pressure and time suggests that the effect of pressure on FRC was progressively larger with the progressively higher pressures.

The one-way repeated measures ANOVAs for the three different pressures showed that FRC was affected by time for zero end-expiratory pressure $(P=0.003)$, $5 \mathrm{~cm} \mathrm{H}_{2} \mathrm{O}$ CPAP $(P<0.001)$ and $10 \mathrm{~cm} \mathrm{H}_{2} \mathrm{O}$ CPAP $(P<0.001)$. The two-tailed Dunnett's test results showed no significant change in FCR with the application of zero end-expiratory pressure. However, with the application of $5 \mathrm{~cm} \mathrm{H}_{2} \mathrm{O}$ CPAP there was a significant increase at $22 \mathrm{~min}$ in FRC. In the $10 \mathrm{~cm}$ $\mathrm{H}_{2} \mathrm{O}$ condition, FRCs measured at both 12 and $22 \mathrm{~min}$ after the application of CPAP were both significantly larger than the pre-CPAP FRC.

\section{Discussion}

The results of this study are of interest for three reasons. Firstly, they demonstrate that CPAP increases FRC in healthy tetraplegic subjects, although FRC returns to normal soon after the removal of CPAP. Second, and unexpectedly, subjects did not have a decreased FRC, as has been previously reported. Third, it was not possible to detect a CV in our tetraplegic subjects.

In this study, FRC increased by a mean of $9 \%$ and $34 \%$ with the application of 5 and $10 \mathrm{~cm} \mathrm{H}_{2} \mathrm{O}$ of CPAP, respectively. Previous studies that have looked at the effects of similar levels of CPAP on healthy able-bodied subjects have also reported increases in FRC, ${ }^{7,8,9,10}$ although the extent to which FRC has been found to increase is highly variable. These studies 
have reported mean FRC increases of between $16 \%{ }^{9}$ and $50 \%{ }^{10}$ with the application of $5 \mathrm{~cm} \mathrm{H} \mathrm{H}_{2} \mathrm{O}$ of CPAP, and of between $24 \%{ }^{7}$ and $56 \%{ }^{8}$ with the application of $10 \mathrm{~cm} \mathrm{H} \mathrm{H}_{2} \mathrm{O}$ of CPAP. Given the variability in these findings, it is not possible to determine whether the effects of CPAP on healthy tetraplegic subjects are more or less than the effects on other patient groups.

When FRC was measured at 1 and 22 min after the removal of CPAP it did not significantly differ from pre-CPAP values. It would appear, therefore, that any elevating effect of CPAP on FRC is largely lost once CPAP is ceased. Interestingly, Heitz et al ${ }^{10}$ and Stock et $a l^{24}$ also found that FRC was not significantly different from pre-CPAP values shortly $(10 \mathrm{~min})$ after the removal of CPAP.

In this study the mean FRC of the tetraplegic subjects prior to the application of CPAP was $110 \%$ of predicted values. In contrast, previous investigators have reported FRC values of between $49 \%^{19}$ and $88 \%{ }^{15}$ of predicted values in tetraplegic subjects. ${ }^{13,15,18,19,25,26}$ These investigators hypothesize that the decreases in FRC are due to the direct effects of respiratory muscle weakness. ${ }^{13,27}$ The present study is the first to report near normal FRCs in tetraplegic subjects.

It is not immediately obvious why our subjects had near normal FRCs. One explanation relates to our use of relatively recently injured tetraplegic patients. The mean time since injury of our subjects was less than 16 months, with a median time of 12.5 months. In contrast all studies to date have examined tetraplegic patients with a mean time since injury of at least 21 months. ${ }^{13,15,18,19,25,26}$ It is possible that FRC progressively decreases with time after injury, as a consequence of ongoing changes in pulmonary and rib cage compliance. ${ }^{1,28}$ It may be that our subjects had not yet experienced sufficient changes in pulmonary and rib cage compliance to adversely affect FRC. It is difficult to test this hypothesis with the currently available data. However, our data showed a trend towards subjects with more acute lesions having larger FRCs $(P=0.25)$. Similar results were found when the data from all the published studies were pooled. Ultimately longitudinal studies, rather than crosssectional studies, will be required to test the hypothesis that FRC decreases with time since injury.

It was not possible to detect CVs either with or without the application of CPAP, because there was no clear onset of phase 4 with the $\mathrm{SBN}_{2}$ test. This could be interpreted to mean either that the airways of those who are tetraplegic do not close at a discreet volume, or that the $\mathrm{SBN}_{2}$ test is inappropriate for the measurement of $\mathrm{CV}$ in tetraplegics. The $\mathrm{SBN}_{2}$ test may have failed to detect CVs because of the violation of some or all of the assumptions underlying the test. In particular, the test assumes that there are regional differences in the RV : VC ratios. ${ }^{29,30}$ It is possible that such regional differences do not occur in the lungs of those tetraplegics which would have made it impos- sible to establish the necessary nitrogen gradient down the lung after the full inspiration of $100 \% \mathrm{O}_{2}$. The consequence would be that there was no distinct onset of phase 4. Future studies aimed at ascertaining the presence of $\mathrm{CVs}$ in tetraplegic people would benefit from further examination of the regional differences in $\mathrm{RV}$ and VC.

Without measurements of $\mathrm{CV}$ it is difficult to interpret the effect of CPAP on the relationship between FRC and CV. The potential advantage of increasing FRC is that it increases the gap between FRC and CV. ${ }^{4,5,6}$ It has been proposed that widening of the gap between FRC and CV helps to prevent premature airway closure $e^{4,5,6}$ and that by this mechanism CPAP can be used to treat and prevent atelectasis. ${ }^{1,2,3,4}$ While our study has demonstrated increases in FRC with CPAP, it has not been possible to ascertain the affect of CPAP on CV. It would seem unlikely that CPAP would increase CV, but this is yet to be experimentally verified. Until the effects of CPAP on CV are known, it cannot be certain that CPAP prevents or reverses airway closure in tidal breathing.

There are several additional questions that need to be clarified before the therapeutic value of CPAP in tetraplegics is established. Firstly, the effect of CPAP on FRC in tetraplegic patients with respiratory complications needs to be determined. Second, it will be necessary to ascertain the effect of CPAP on the work of breathing in these patients. Large increases in the work of breathing would be detrimental to the overall aims of CPAP. Third, the effect of CPAP on cardiac output in tetraplegics needs to be examined. This is particularly important given the impaired cardiovascular control of such persons. ${ }^{16}$ Without answers to these questions, it cannot necessarily be assumed that any respiratory benefits derived from CPAP would result in an increase in the delivery of oxygen to the peripheral tissues.

In conclusion, this study has demonstrated that 5 and $10 \mathrm{~cm} \mathrm{H}_{2} \mathrm{O}$ of CPAP significantly increases FRC in healthy tetraplegic people, but that this increase is largely reversed within 1 min of the removal of CPAP. These results suggest that CPAP may be an effective way of inducing transient increases in FRC. Even transient increases in FRC may widen the gap between FRC and CV and thereby help in both the treatment and prevention of atelectasis. However, to ascertain the precise therapeutic role of CPAP in people who are tetraplegic it will be necessary to examine the respiratory and cardiac effects of CPAP in tetraplegic patients with respiratory complications.

\section{Acknowledgements}

We would like to thank Professor Tom Torda, Dr Geoff Field, Dr Joy Higgs, Jenny Alison, Phillip Balnave, Geoff Foot, Irene $\mathrm{Ng}$, Dr Eugene Chekaluk and $\mathrm{Dr}$ Roger Adams. 


\section{References}

1 Anderes C, Anderes U, Gasser D, Dittmann M, Turner J, Brennwald J, Keller R, Ferstl A, Wolf G. Postoperative spontaneous breathing with CPAP to normalise late postoperative oxygenation. Intensive Care Med 1979; 5: 15-21.

2 Andersen JB, Olesen KP, Eikard B, Jansen E, Qvist J. Periodic continuous positive airway pressure, CPAP, by mask in the treatment of atelactasis. Eur J Respir Dis 1980; 61: 20-25.

3 Duncan SR, Negrin RS, Mihm FG, Guilleminault C, Ruffin TA. Nasal continuous positive airway pressure in atelactasis. Chest 1987; 92: $621-624$.

4 Ricksten S, Bengtsson A, Soderberg C, Thorden M, Kvist H. Effects of periodic positive airway pressure by mask on postoperative pulmonary function. Chest 1986; 89: 774-781.

5 Craig DB, Wahba WM, Don HF, Coulture JG, Becklake MR. 'Closing volume' and its relationship to gas exchange in seated and supine positions. J Appl Physiol 1971; 31: 717-721.

6 Miller RF, Semple SJ. Continuous positive airway pressure ventilation for respiratory failure associated with Pneumocystis carinii pneumonia. Respir Med 1991; 85: 133-138.

7 Abboud N, Rehder K, Rodarte J, Hyatt R. Lung volumes and closing capacity with continuous positive airway pressure. Anesthesiology 1975; 42: 138-142.

8 Craig DB, McCarthy DS. Airway closure and lung volumes during breathing with maintained airway positive pressure. Anesthesiology 1972; 36: $540-543$.

9 Gherini S, Peters RM, Virgilio RW. Mechanical work on the lungs and work of breathing with positive end-expiratory pressure and continuous positive airway pressure. Chest 1979; 76: $251-256$

10 Heitz M, Holzach P, Dittmann M. Comparison of the effect of continuous positive airway pressure and blowing bottles on functional residual capacity after abdominal surgery. Respiration 1985; 48: $277-284$.

11 Gregory GA, Edmunds LH, Kitterman JA, Phibbs RH, Tooley WH. Continuous positive airway pressure and pulmonary and circulatory function after cardiac surgery in infants less than 3 months of age. Anesthesiology 1975; 43: 426-431.

12 Stock MC, Downs JB, Gauer PK, Alster JM, Imrey PB. Prevention of postoperative pulmonary complications with CPAP, incentive spirometry, and conservative therapy. Chest 1985; 87: $151-157$.

13 De Troyer A, Heilporn A. Respiratory mechanics in quadriplegia. The respiratory function of the intercostal muscles. Am Rev Respir Dis 1980; 122: 591-600.

14 De Troyer A, Deisser P. The effects of intermittent positive pressure breathing on patients with respiratory muscle weakness. Am Rev Respir Dis 1981; 124: 132 - 137.
15 De Troyer A, Estenne M, Heilporn A. Mechanism of active expiration in tetraplegic subjects. $N$ Eng J Med 1986; 314: 740 744.

16 Mansel JK, Norman JR. Respiratory complications and managemant of spinal cord injuries. Chest 1990; 97: 1446- 1452.

17 De Troyer A, Pride NB. The respiratory system in neuromuscular disorders. In: Roussos C, Macklem PT. (eds.) The Thorax. Lung Biology in Health and Disease. New York: Marcel Dekker, 1985; pp $1089-1121$.

18 Fugl-Meyer AR, Grimby G. Ventilatory function in tetraplegic patients. Scand J Rehabil Med 1971; 3: 151-160.

19 Scanlon PD, Loring SH, Pichurko BM, McCool FD, Slutsky AS, Sarkarati M, Brown R. Respiratory mechanics in acute quadripelgia. Lung and chest wall compliance and dimensional changes during respiratory maneuvers. Am Rev Respir Dis 1989; 139: $615-620$.

20 Buist AS, Ross BB. Predicted values for closing volumes using a modified single breath nitrogen test. Am Rev Respir Dis 1973; 107: $744-752$.

21 Working Party, European Community for Coal and Steel. Standardized lung function testing. Clin Respir Physiol 1983, 19: Suppl 5: 45-51.

22 Schroutt PE, Fleiss JL. Intraclass correlations: uses in assessing rater reliability. Psych Bull 1979; 86: $420-428$.

23 Winer BJ. Statistical principles in experimental design. New York: McGraw-Hill, 1962; pp 353-369.

24 Stock MC, Downs JB, Corkran ML. Pulmonary function before and after prolonged continuous positive airway pressure by mask. Crit Care Med 1984; 12: 973 -974.

25 Estenne M, De Troyer A. Mechanism of the postural dependence of vital capacity in tetraplegic subjects. Am Rev Respir Dis 1987; 135: $367-371$.

26 Fugl-Meyer AR, Grimby G. Rib-cage and abdominal volume ventilation partitioning in tetraplegic patients. Scand J Rehabil Med 1971; 3: $161-167$.

27 Gibson GJ, Pride NB, Newsom Davis J, Loh LC. Pulmonary mechanics in patients with respiratory muscle weakness. Am Rev Respir Dis 1977; 115: 389-395.

28 Estenne M, De Troyer A. The effects of tetraplegia on chest wall statics. Am Rev Respir Dis 1986; 134: $121-124$.

29 Knudson DJ, Lebowitz MD, Burton AP, Knudson DE. The closing volume test: evaluation of nitrogen and bolus methods in a random population. Am Rev Respir Dis 1977; 115: 423-434.

30 Travis DM, Green M, Don H. Simultaneous comparison of helium and nitrogen expiratory 'closing volumes'. J Appl Physiol 1973; 34: $304-308$ 